\title{
Penggunaan integer linier programming untuk meminimumkan ruang kuliah pada Mata Kuliah Dasar Umum (MKDU) Studi Kasus di Universitas Tribuana Kalabahi
}

Damaris Lalang ${ }^{1 *}$, Dewi Rosalina Alojaha ${ }^{1}$

${ }^{1}$ Fakultas Matematika dan Ilmu pengetahuan Alam, Universitas Tribuana Kalabahi, Kalabahi, Alor - NTT, Indonesia, *email korespondensi: dhamar.ipb14@gmail.com

\section{Article Info}

\section{Article history:}

Received: 15 Desember 2021

Received in revised form: 20 Desember 2021

Accepted: 25 Desember 2021

\section{Doi: https://doi.org/10.32938/slk.v4i2.1554}

\section{Keywords:}

penjadwalan MKDU,

integer linier programming

\begin{abstract}
Abstrak
Penjadwalan mata kuliah merupakan salah satu masalah yang sering dialami oleh Suatu Perguruan Tinggi. Begitu jug yang dialami oleh Universitas Tribuana Kalabahi (UNTRIB). Penjadwalan mata kuliah di UNTRIB terdiri dari dua skema penjadwalan yaitu penjadwalan mata kuliah Program Studi dan penjadwalan Mata Kuliah Dasar Umum. Penjawalan Mata Kuliah Program Studi di susun oleh Program Studi sedangkan untuk MKDUdi susun oleh tim di unit MKDU pada setiap awal semester. Proses penjadwalan dilakukan secara manual, dengan mengambil jadwal mata kuliah di setiap Program Studi yang ada di UNTRIB, setelah itu dari MKDU mulai menyusun penjawalan mata kuliah dengan menyesusaikan penjadwalan mata kuliah dari program studi yang sudah ada. Integer linier programming (ILP) adalah metode yang dapat dimodelkan persoalan penjadwalan dengan berbagai kendala yang dapat disesuaikan dengan kebutuhan Universitas, dan ILP bisa digunakan untuk membuat penjadwalan MKDU dengan menggunakan perangkat lunak Lingo 11.0. Tujuan penelitian ini adalah Meminimumkan ruang kuliah agar tidak terjadi bentrokan saat perkuliahan berlangsung. Dari hasil penelitian ini menyatakan bahwa awalnya menggunakan 20 ruang kuliah dapat diminumkan menjadi 5 ruang kuliah dengan slot waktu yang disesuaikan.
\end{abstract}

\section{Pendahuluan}

Dalam organisasi dengan sumber daya besar, penjadwalan adalah salah satu factor terpenting dari strategi manajemen dan yang paling rentan terhadap kesalahan atau masalah (Oktavia dkk., 2017). Penjadwalan pun sering dilakukan oleh universitas. Penjadwalan yang dimaksud disini adalah penjadwalam mata kuliah. Sistem penjadwalan ini juga yang di alami di universitas Tribuana Kalabahi (UNTRIB) pada setiap tahun ajaran baru. UNTRIB sendiri menerapkan penjadwalan mata kuliah yang terdiri dari dua penjadwalan yaitu penjadwalan mata kuliah program studi dan penjadwalan mata kuliah dasar umum (MKDU). Untuk penjadwalan mata kuliah program studi di susun oleh program studi sedangkan untuk MKDU di susun oleh unit MKDU pada setiap awal semester. Universitas Tribuana Kalabahi terdapat 19 ruangan yang digunakan untuk proses perkuliahan mata kuliah dasar umum berlangsung. Dari 19 ruangan yang tersedia untuk perkuliahan berlangsung namun masih terjadi tabrakan dosen yang mengajar dan tabrakan penggunaan ruangan perkuliahan. Jumlah dosen yang mengajar mata kuliah dasar umum di Universitas Tribuana Kalahahi pada semester ganjil adalah 24 dosen yang terdiri dari dosen tetap di Universitas Tribuana Kalabihi dan juga dosen luar biasa. Proses penjadwalan dilakukan secarah manual dengan mengambil jadwal mata kuliah program studi di setiap program studi, sedangkan MKDU diambil langsung di unit MKDU, kemudian mulai menyusun MKDU dengan menyesusaikan penjadwalan mata kuliah dari program studi yang sudah ada. Penggunaan ruangan perkuliahan juga menjadi kendala dalam proses perkuliahan berlangsung Penjadwalan yang selama ini dilakukan sudah cukup membantu dalam jalannya proses belajar mengajar. Namun masih ditemukan masalah dalam penjadwalan mata kuliah, khususnya penjadwalan mata kuliah dasar umum (MKDU), seperti tabrakan jadwal kuliah pada dosen dan juga tabrakan penggunaan ruangan yang tersedia sehingga jadwal yang sudah di buat seringkali diperbaiki, membuat proses belajar mengajar tidak efisien. Supaya proses penjadwalan lebih efisien dan tidak terjadi pelanggaran terhadap ruangan yang digunakan, serta meminimalkan pelanggaran tersebut maka perlu dibuat sistem penjadwalan yang tepat.

Proses penjadwalan yang tepat dapat diselesaikan menggunakan metode Integer Linier Progamming. Penjadwalan mata kuliah dengan menggunakan integer linier programming merupakan model program linier dengan persyaratan tambahan yaitu beberapa atau semua variabel keputusan harus merupakan bilangan bulat. Penggunaan variabel bilangan bulat memberikan tambahan fleksibilitas dalam pembuatan model (Anderson, dkk., 1996), metode ini sangat membantu dalam penjadwalan mata kuliah karena menghasilkan jadwal yang memenuhi semua kendala dalam waktu yang relatif cepat. Batasan-batasan tersebut adalah batasan mutlak yakni batasan yang tidak boleh dilanggar, contohnya satu mata kuliah yang dijadwalkan pada satu waktu dan ruang diampu oleh seorang dosen tidak bersamaan dengan mata kuliah lain yang diampu oleh dosen lain. Sedangkan batasan lunak atau batasan yang boleh dilanggar namun Sebisa mungkin pelanggaran tersebut diminimalkan, contohnya adalah jadwal menyesuaikan permintaan dosen atau disesuaikan prioritas dosen.

Masalah penjadwalan mata kuliah atau penjadwalan lainnya sebenarnya sudah banyak dibahas antara lain, model integer programming (studi kasus pada jurusan teknik industri fakultas teknik universitas patimura ambon). Penjadwalan saat ini memegang peranan yang sangat penting dalam proses perencanaan maupun pada proses pengendalian baik dalam bidang industri atau bidang lainnya termasuk juga dalam bidang pendidikan seperti penjadwalan ujian sarjana. hal ini juga menjadi pemasalahan yang ada pada Jurusan Teknik Industri, Fakultas Teknik Universitas Pattimura (Maspaitella dan Tupan, 2016). Dalam penelitian ini yang dibahas adalah bagaimana membuat model penjadwalan yang sesuai dengan kebutuhan sistem yang ada pada jurusan tersebut agar lebih efektif.
Metode yang digunakan dalam penelitian ini yaitu Integer Programming Penelitian ini menghasilkan output berupa model yang telah disesuaikan dengan sistem yang ada pada jurusan itu, dimana model ini dapat digunakan untuk membuat penjadwalan ujian sarjana. Penelitian selanjutnya membahas tentang aplikasi Integer Linier Programming (ILP) untuk meminimumkan biaya produksi pada siaputo aluminium: Penelitian ini bertujuan untuk menyelesaikan masalah optimisasi, khusunya meminimumkan biaya produksi dengan menggunakan Integer Linear Programming (ILP) selain penelitian di yang dijabarkan di atas, ada juga beberapa penelitian lain yang sudah dilakukan oleh Hikma (2015), Khairunnisa (2015), Huda, dkk. (2016), Blegur dan Binsas (2020), dan Daskalaki dkk. (2004). Ada juga penelitian Ruhiyati (2015) merumuskan masalah penjadwalan sebagai model pemrograman bilangan bulat (0-1), untuk meminimalkan ketidakpuasan mahasiswa dan dosen sementara pada saat bersamaan menerapkan peraturan yang dibatasi oleh serangkaian kendala sedangkan penelitian Daskalaki (2008) membuat model penjadwalan mata kuliah kurikulum mayor-minor di perguruan tinggi.

Merujuk dari penelitian yang sudah pernah dilakukan maka tujuan dari penelitian ini adalah untuk menerapkan metode Integer Linier Progamming dalam meminimumkan ruang kuliah yang digunakan untuk mata kuliah dasar umum agar tidak ada lagi bentrokan ruangan.

\section{Metode}

Metode yang digunakan dalam penelitian ini adalah dengan menggunakan Integer Linier Progamming. Langkah-langkah sebagai berikut:

a. Studi literatur

Pada awal penelitian dilakukan studi literatur dari buku dan jurnal untuk menggali informasi terkait penjadwalan ruangan menggunakan Integer Linear Programming

b. Pengumpulan data (Observasi)

Pada tahap ini menghimpun informasi-informasi mengenai kebutuhan sistem, alur penjadwalan dan informasi-informasi lainnya dari para penyusun penjadwalan ruangan yang digunakan MKDU

c. Memodelkan masalah dan menyelesaikan

Pada tahap ketiga memodelkan masalah dengan menentukan variabel keputusan, fungsi tujuan, dan fungsi kedala. Setelah itu meyelesaikan masalah dengan menggunakan Integer Linier Progamming.

\subsection{Deskripsi Masalah}

Universitas Tribuana Kalabahi menerapakan dua mata kuliah yakni mata kuliah program studi dan juga mata kuliah dasar umum (MKDU). Salah satu tugas dari unit mata kuliah dasar umum adalah membuat penjadwalan MKDU yang dialokasikan untuk 10 program studi, data di ambil dari unit MKDU. Masalah penjadwalan mata kuliah dasar umum di universitas Tribuana Kalabahi adalah meminimumkan ruangan perkuliahan. Diikuti 20 rombongan belajar yang diakumulasi dari 10 program studi. Dari 20 rombongan belajar di kelompokan menjadi kelompok P dan kelompok Q. Kelompok P terdiri atas 10 kelas rombongan belajar mahasiswa dan kelompok Q terdiri 10 kelas rombongan belajar mahasiswa. Mata kuliah yang diikuti masing-masing kelompok kelas sebanyak 10 mata kuliah, serta waktu yang ditetapkan mulai dari hari senin sampai sabtu dengan 7 periode waktu setiap harinya dengan pembagian kelas pagi dan sore. Masalah yang dicontokan dalam studi kasus ini adalah masalah penjadwalan MKDU emester ganjil. Hal yang perlu di perhatikan adalah banyaknya rombongan belajar dengan ruangan yang terbatas. Unit MKDU telah menentukan bahwa setiap satu jam perkuliahan dilakukan selama 50 menit. Data yang diperlukan untuk memodelkan penjadwalan MKDU adalah sebagai berikut: 
Tabel 1. Hari Perkuliahan

\begin{tabular}{cc}
\hline Indeks $(i)$ & Hari \\
\hline 1 & Senin \\
2 & Selasa \\
3 & Rabu \\
4 & Kamis \\
5 & Jumat \\
6 & Sabtu \\
\hline
\end{tabular}

Dari tabel 1 dapat dilihat jumlah hari perkuliahan yang digunakan 6 hari yaitu dari hari senin sampai hari sabtu.

Tabel 2. Periode Waktu

\begin{tabular}{ll}
\hline Indeks $(j)$ & Periode waktu \\
\hline 1 & $07.00-08.40$ \\
2 & $08.50-10.30$ \\
3 & $10.40-12.20$ \\
4 & $12.30-14.10$ \\
5 & $14.20-16.00$ \\
6 & $16.10-17.50$ \\
7 & $18.00-19.40$ \\
\hline
\end{tabular}

Tabel 2, menjelaskan tentang periode waktu perkuliahan MKDU dengan periode waktu 07.00-18.00-19.40 dengan jeda waktu 10 menit.

Tabel 3. Mata Kuliah

\begin{tabular}{cl}
\hline Indeks $(m)$ & Mata kuliah \\
\hline 1 & Bahasa Indonesia \\
2 & Panasila \\
3 & Agama Kristen \\
4 & IAD \\
5 & ISBD \\
6 & MSP \\
7 & Etika Kristen \\
8 & Bahasa inggris I \\
9 & Bahasa inggris II \\
10 & Bahasa inggris ekonomi \\
\hline
\end{tabular}

Tabel 3, menjelaskan adanya 9 MKDU, khususnya pada semester ganjil.

Tabel 4. Rombongan Belajar

\begin{tabular}{cccc}
\hline Indeks $(k)$ & Rombongan belajar & Indeks $(k)$ & $\begin{array}{l}\text { Rombongan } \\
\text { belajar }\end{array}$ \\
\hline 1 & P1 & 11 & Q1 \\
2 & P2 & 12 & Q2 \\
3 & P3 & 13 & Q3 \\
4 & P4 & 14 & Q4 \\
5 & P5 & 15 & Q5 \\
6 & P6 & 16 & Q6 \\
7 & P7 & 17 & Q7 \\
8 & P8 & 18 & Q8 \\
9 & P9 & 19 & Q9 \\
10 & P10 & 20 & Q10 \\
\hline
\end{tabular}

Pada tabel 4, menjelaskan benyaknya rombongan belajar yang ada di universitas tribuana kalabahi, yang di akumulasikan menjadi rombongan belar $\mathrm{P}$ dan rombongan belajar Q.

\subsection{Formulasi Masalah}

Dari masalah tersebut dapat di formulasikan dengan integer linier programming (ILP), dengan menggunakan indeks, himpunan, parameter, dan variable keputusan sebagai beikut.

\section{INDEKS}

\section{Simbol keterangan}

$i=\quad$ menyatakan hari

$j=\quad$ menyatakan periode waktu

$k=\quad$ menyatakan rombongan belajar

$m=\quad$ untuk menyatakan mata kuliah

$n=\quad$ untuk menyatakan tipe mata kuliah

\section{Himpunan}

\section{Simbol keterangan}

$I=$ hari $=\{1,2,3, \ldots, 6\}$

$J \quad=$ periode waktu $=\{1,2,3, . ., 7\}$

$\mathrm{K}=$ rombongan belajar $=\{1,2,3, \ldots 20\}$

$K_{1} \quad=$ rombongan belajar $P, K_{1} \subseteq K=\{1,2,3, . .10\}$

$K_{2}=$ rombongan belajar $Q, K_{2} \subseteq K=\{11,12,13, \ldots 20\}$

$\mathrm{M}=$ mata kuliah $=\{1,2,3, . .10\}$

$M_{1}=$ mata kuliah untuk rombonhan belajar $P, M_{1} \subseteq M=\{1,2,3, . .5\}$

\section{Parameter}

$S$ = ruangan yang tersedia $=19$

$R=$ mata kuliah yang diambil $=10$

\section{Variable keputusan}

$H$ = ruangan yang akan digunakan

$t_{i j} \quad=$ ruangan yang terjadwalkan di hari $i$ periode waktu $j$

$t_{1(i, j)}=$ ruangan yang terjadwalkan di hari $i$ periode waktu $j$ untuk rombongan belajar $P$

$t_{2(i, j)}=$ ruangan yang terjadwalkan di hari $i$ periode waktu $j$ untuk rombongan belajar $Q$

$X_{i j k m n}$
$=\left\{\begin{array}{c}1, j i k a \text { hari i periode waktu } j \text { untuk kelompok } k \text { dijadwalkan } \\ \text { untuk mata kuliah } m \text { bertipe } n \text { yang terjadwalkan } \\ 0, \text { jika selainnya }\end{array}\right.$

$Y_{i k m n}$

$=\{1, j i k a$ mata kuliah $m$ bertipe $n$ dijadwalkan untuk kelompok $k$ di hari $i$

$=\{$, jika selainnya

\section{Fungsi objektif}

Fungsi objektif adalah meminimumkan jumlah ruangan yang digunakan.

$t_{1(i, j)}=\sum_{k=1}^{10} \sum_{m-1}^{5} \sum_{n=1}^{2} X_{i j k m n} \forall i \in I, \forall j \in J$

$t_{2(i, j)}=\sum_{k=11}^{20} \sum_{m=6}^{10} \sum_{n=1}^{2} X_{i j k m n} \forall i \in I, \forall j \in J$

Dan $H \geq t_{1(i, j}+t_{2(i, j)}$, fungsi objektifnya ialah meminimumkan $H$

Kendala-kendala

1. Setiap mata kuliah pada 1 periode waktu hanya dihadiri satu kelompok $\sum_{m=1}^{5} \sum_{n=1}^{2} X_{i j k m n} \leq 1, \forall i \in I, \forall j \in J, \forall k \in$ $k_{1}$

$$
\sum_{k_{2}}^{10} \sum_{n=1}^{2} X_{i j k m n} \leq 1, \forall i \in I, \forall j \in J, \forall k \in
$$

2. Setiap solusi penjadwalan hanya boleh diambil 1 kali oleh setiap rombongan belajar dalam satu minggu

$$
\begin{aligned}
& \sum_{\mathrm{i} \in \mathrm{I}} Y_{i k m n}=1, \forall m \in M_{1}, \forall n \in N \\
& \sum_{\mathrm{i} \in \mathrm{I}} Y_{i k m n}=1, \forall m \in M_{2}, \forall n \in N
\end{aligned}
$$

3. Banyaknya ruangan yang tersedia harus lebih banyak dari banyaknya ruangan yang terjadwalkan

$$
\begin{aligned}
& S \geq \sum_{k=1}^{10} \sum_{m=1}^{5} X_{i j k m n}, \forall i \in I, \forall j \in J, \forall n \in N \\
& S \geq \sum_{k=11}^{20} \sum_{m=6}^{10} X_{i j k m n}, \forall i \in I, \forall j \in J, \forall n \in N
\end{aligned}
$$

4. Setiap rombongan belajar harus mengambil 5 mata kuliah yang di sediakan

$$
\sum_{i=1}^{6} \sum_{m=1}^{5} \sum_{n=1}^{2} Y_{i k m n}=5.2, \forall k \in k_{1}
$$$$
\sum_{i=1}^{6} \sum_{m=6}^{10} \sum_{n=1}^{2} Y_{i k m n}=5.2, \forall k \in k
$$

5. Setiap rombongan belajar harus kuliah maksimal 6 hari dalam seminggu

$\sum_{i=1}^{6} \sum_{k=1}^{10} \sum_{m=1}^{5} \sum_{n=1}^{2} X_{i j k m n} \leq 24, \forall j \in J$
$\sum_{i=1}^{6} \sum_{k=11}^{20} \sum_{m=6}^{10} \sum_{n=1}^{2} X_{i j k m n} \leq 24, \forall j \in J$

6. Setiap mata kuliah harus dijadwalkan sesuai periode waktu dalam 1 hari $\sum_{j}^{7} X_{i j k m n}-Y_{k m n}=0, \forall i \in I, \forall k \in K_{1}, \forall m \in M_{1}, \forall n \in N$ $\sum_{j}^{7} X_{i j k m n}-Y_{k m n}=0, \forall i \in I, \forall k \in K_{2}, \forall m \in M_{2}, \forall n \in N$

7. Semua variable keputusan adalah integer 0 atau 1 $X i j k m n \in\{0,1\}, \forall i \in I, \forall j \in J, \forall k \in K, \forall m \in M, \forall n \in N$ Yikmn $\in\{0,1\}, \forall i \in I, \forall j \in J, \forall k \in K, \forall m \in M, \forall n \in N$

\section{Hasil dan Pembahasan}

Masalah penjadwalan mata kuliah dasar umum (MKDU), di selesaikan dengan software LINGO 11.0. Solusi yang di dapat adalah solusi optimal. Fungsi objektifnya:

$$
\begin{gathered}
t_{1(i, j)}=\sum_{k=1}^{10} \sum_{m-1}^{5} \sum_{n=1}^{2} X_{i j k m n} \forall i \in I, \forall j \in J \\
t_{2(i, j)}=\sum_{k=11}^{20} \sum_{m=6}^{10} \sum_{n=1}^{2} X_{i j k m n} \forall i \in I, \forall j \in J
\end{gathered}
$$

Maka fungsi tujuan dapat ditulis sebagai berikut $H \geq t_{1(i, j}+t_{2(i, j)}$, seperti pada tabel 8: 
Tabel 5. Jadwal MKDU Rombongan Belajar $P$

\begin{tabular}{|c|c|c|c|}
\hline Hari & $\begin{array}{l}\text { Periode waktu } \\
\text { (jam) }\end{array}$ & $\begin{array}{l}\text { Kelompok } \\
\text { mahasiswa }\end{array}$ & Mata kuliah \\
\hline \multirow[t]{3}{*}{ Senin } & $12.30-14.10$ & P1 & IAD \\
\hline & $16.10-17.50$ & & Bahasa inggris II \\
\hline & $18.00-19.40$ & & Agama Kristen \\
\hline \multirow[t]{2}{*}{ Selasa } & $08.50-10.30$ & P1 & Etika Kristen \\
\hline & $10.40-12.20$ & & Bahasa Indonesia \\
\hline \multirow[t]{2}{*}{ Rabu } & $12.20-14.10$ & P1 & ISBD \\
\hline & $14.20-16.00$ & & Pancasila \\
\hline \multirow[t]{2}{*}{ Kamis } & $10.40-12.20$ & P1 & Bahasa inggris I \\
\hline & $16.10-17.50$ & & Pancasila \\
\hline Sabtu & $08.50-10.30$ & P1 & MSP \\
\hline Senin & $14.20-16.00$ & $\mathrm{P} 2$ & Pancasila \\
\hline \multirow[t]{4}{*}{ Selasa } & $07.00-08.40$ & P2 & Bahasa Indonesia \\
\hline & $14.20-16.0$ & & ISBD \\
\hline & $16.10-17.50$ & & Agama Kristen \\
\hline & $18.00-19.40$ & & MSP \\
\hline Rabu & $07.00-08.40$ & P2 & Bahasa inggris I \\
\hline \multirow[t]{2}{*}{ Jumat } & $14.20-16.00$ & P2 & IAD \\
\hline & $16.10-17.50$ & & Bahasa inggris II \\
\hline \multirow[t]{2}{*}{ Sabtu } & $10.40-12.20$ & P2 & Agama Kristen \\
\hline & $12.30-14.10$ & & Pancasila \\
\hline \multirow[t]{3}{*}{ Senin } & $07.00-08.40$ & P3 & IAD \\
\hline & $08.50-10.30$ & & ISBD \\
\hline & $10.40-12.20$ & & Agama Kristen \\
\hline \multirow[t]{2}{*}{ Kamis } & $07.00-08.40$ & P3 & $\begin{array}{l}\text { Pancasila } \\
\text { Pand }\end{array}$ \\
\hline & $14.20-16.00$ & & Bahasa inggris II \\
\hline Jumat & $07.00-08.40$ & P3 & Pancasila \\
\hline \multirow[t]{4}{*}{ Sabtu } & $07.00-08.40$ & P3 & Agama Kristen \\
\hline & $10.40-12.20$ & & Bahasa inggris I \\
\hline & $12.30-14.10$ & & Bahasa Indonesia \\
\hline & $14.20-16.00$ & & MSP \\
\hline Senin & $07.00-08.40$ & P4 & ISBD \\
\hline & $10.40-12.20$ & & Agama Kristen \\
\hline & $12,30-14.10$ & & IAD \\
\hline & $14.20-16.00$ & & Pancasila \\
\hline & $16.10-17.50$ & & Agama Kristen \\
\hline Selasa & $10.40-12.20$ & P4 & Bahasa Indonesia \\
\hline & $12.30-14.10$ & & Pancasila \\
\hline Rabu & $16.10-17.50$ & P4 & Bahasa inggris ekonomi I \\
\hline & $18.00-19.40$ & & Bahasa inggris I \\
\hline Kamis & $10.40-12.20$ & P4 & Bahasa inggris II \\
\hline Senin & $08.50-10.30$ & P5 & ISBD \\
\hline & $10.40-12.20$ & & Agama Kristen \\
\hline & $18.00-19.40$ & & Bahasa Indonesia \\
\hline Selasa & $07.00-08.40$ & P5 & Pancasila \\
\hline & $10.40-12.20$ & & Agama Kristen \\
\hline Rabu & $18.00-19.40$ & P5 & Bahasa inggris I \\
\hline Kamis & $07.00-08.40$ & P5 & IAD \\
\hline Jumat & $10.40-12.20$ & P5 & \\
\hline & $16.10-17.50$ & & Pancasila \\
\hline Sabtu & $16.10-17.50$ & P5 & \\
\hline Senin & $08.50-10.30$ & P6 & Agama Kristen \\
\hline Senin & $16.10-17.50$ & P6 & Bahasa inggris I \\
\hline Selasa & $08.50-10.30$ & P6 & Bahasa Indonesia \\
\hline & $10.40-12.20$ & & \\
\hline Rabu & $16.10-17.50$ & P6 & Pancasila \\
\hline Kamis & $10.40-12.20$ & P6 & ISBD \\
\hline Jumat & $16.10-17.50$ & P6 & Pancasila \\
\hline & $18.00-19.40$ & & \\
\hline Sabtu & $14.20-16.00$ & P6 & Pancasila \\
\hline & $16.10-17.50$ & & \\
\hline Senin & $14.20-16.00$ & P7 & ISBD \\
\hline Selasa & $07.00-08.40$ & P7 & Bahasa Indonesia \\
\hline Rabu & $08.50-10.30$ & P7 & Pancasila \\
\hline & $12.30-14.10$ & & Agama Kristen \\
\hline Kamis & 07.00-08.40 & P7 & \\
\hline Jumat & $12.30-14.10$ & P7 & Pancasila \\
\hline & $14.20-16.00$ & & \\
\hline Sabtu & $08.50-10.30$ & P7 & \\
\hline & $14.20-16.00$ & & \\
\hline & $18.00-19.40$ & & \\
\hline Senin & $08.50-10.30$ & P8 & ISBD \\
\hline & $14.20-16.00$ & & Bahasa Indonesia \\
\hline Kamis & $18.00-19.40$ & P8 & \\
\hline Jumat & $07.00-08.40$ & P8 & Pancasila \\
\hline
\end{tabular}

\begin{tabular}{llll} 
& $12.30-14.10$ & & Agama Kristen \\
Sabtu & $16.10-17.50$ & & \\
& $07.00-08.40$ & $\mathrm{P} 8$ & \\
& $10.40-12.20$ & & \\
& $16.10-17.50$ & & \\
Senin & $18.00-19.40$ & & Bahasa Indonesia \\
Rabu & $14.20-16.00$ & $\mathrm{P} 9$ & \\
Kamis & $08.50-10.30$ & $\mathrm{P} 9$ & ISBD \\
& $07.00-08.40$ & $\mathrm{P} 9$ & Pancasila \\
& $10.40-12.20$ & & Agama Kristen \\
Jumat & $12.30-14.10$ & & \\
Jumat & $10.40-12.20$ & $\mathrm{P} 9$ & \\
Sabtu & $14.20-16.00$ & $\mathrm{P} 9$ & \\
& $10.40-12.20$ & $\mathrm{P} 9$ & \\
& $12.30-14.10$ & & \\
Senin & $16.10-17.50$ & & \\
& $12.30-14.10$ & $\mathrm{P} 10$ & Pancasila \\
& $16.10-17.50$ & & \\
Rabu & $18.00-19.40$ & & \\
Kamis & $18.00-19.40$ & $\mathrm{P} 10$ & ISBD \\
Jumat & $18.00-19.40$ & $\mathrm{P} 10$ & \\
& $07.00-08.40$ & $\mathrm{P} 10$ & \\
& $10.40-12.20$ & & \\
& $12.30-14.10$ & & \\
Sabtu & $18.00-19.40$ & & \\
\hline
\end{tabular}

Tabel 6. Jadwal MKDU Rombongan Belajar Q

\begin{tabular}{|c|c|c|c|}
\hline Hari & $\begin{array}{l}\text { Periode waktu } \\
\text { (jam) }\end{array}$ & $\begin{array}{l}\text { Kelompok } \\
\text { mahasiswa }\end{array}$ & Mata kuliah \\
\hline \multirow[t]{4}{*}{ Kamis } & $12.30-14.10$ & Q1 & Bahasa Indonesia \\
\hline & $14.20-16.00$ & & ISBD \\
\hline & $16.10-17.50$ & & $\begin{array}{l}\text { Bahasa inggris } \\
\text { ekonomi I }\end{array}$ \\
\hline & $18.00-19.40$ & & IAD \\
\hline \multirow[t]{6}{*}{ Jumat } & $07.00-08.40$ & Q1 & Bahasa inggris II \\
\hline & $08.50-10.30$ & & Agama Kristen \\
\hline & $10.40-12.20$ & & Pancasila \\
\hline & $12.30-14.10$ & & Bahasa inggris I \\
\hline & $14.20-16.00$ & & Etika Kristen \\
\hline & $18.00-19.40$ & & MSP \\
\hline Selasa & $14.20-16.00$ & Q2 & Agama Kristen \\
\hline \multirow[t]{7}{*}{ Rabu } & $07.00-08.40$ & $\mathrm{Q} 2$ & Pancasila \\
\hline & $08.50-10.30$ & & ISBD \\
\hline & $10.40-12.20$ & & \\
\hline & $12.30-14.10$ & & Pancasila \\
\hline & $14.20-16.00$ & & Bahasa Indonesia \\
\hline & $16.10-17.50$ & & MSP \\
\hline & $18.00-19.40$ & & IAD \\
\hline \multirow[t]{2}{*}{ Kamis } & $10.40-12.20$ & Q2 & \\
\hline & $12.30-14.10$ & & Bahasa inggris I \\
\hline Senin & $07.00-08.40$ & Q3 & ISBD \\
\hline \multirow[t]{3}{*}{ Selasa } & $07.00-08.40$ & Q3 & Pancasila \\
\hline & $08.50-10.30$ & & Agama Kristen \\
\hline & $14.20-16.00$ & & Bahasa inggris I \\
\hline Selasa & $18.00-19.40$ & Q3 & Pancasila \\
\hline \multirow[t]{4}{*}{ Rabu } & $07.00-08.40$ & Q3 & IAD \\
\hline & $08.50-10.30$ & & Bahasa inggris II \\
\hline & $10.40-12.20$ & & Bahasa Indonesia \\
\hline & $12.30-14.10$ & & MSP \\
\hline Kamis & $08.50-10.30$ & Q3 & Pancasila \\
\hline Senin & $08.50-10.30$ & Q4 & Agama Kristen \\
\hline \multirow[t]{2}{*}{ Selasa } & $08.50-10.30$ & Q4 & Pancasila \\
\hline & $12.30-14.10$ & & Bahasa Indonesia \\
\hline \multirow[t]{3}{*}{ Rabu } & $10.40-12.20$ & Q4 & ISBD \\
\hline & $14.20-16.00$ & & \\
\hline & $18.00-19.40$ & & Bahasa inggris I \\
\hline \multirow[t]{3}{*}{ Kamis } & $08.50-10.30$ & Q4 & IAD \\
\hline & $12.30-14.10$ & & Pancasila \\
\hline & $14.20-16.00$ & & Pancasila \\
\hline Jumat & $08.50-10.30$ & Q4 & \\
\hline \multirow[t]{3}{*}{ Senin } & $07.00-08.40$ & Q5 & Pancasila \\
\hline & $12.30-14.10$ & & \\
\hline & $18.00-19.40$ & & Agama Kristen \\
\hline \multirow[t]{2}{*}{ Selasa } & $14.20-16.00$ & Q5 & IAD \\
\hline & $18.00-19.40$ & & ISBD \\
\hline Rabu & $10.40-12.20$ & Q5 & Agama Kristen \\
\hline \multirow[t]{3}{*}{ Kamis } & $07.00-08.40$ & Q5 & Bahasa inggris I \\
\hline & $08.50-10.30$ & & Bahasa Indonesia \\
\hline & $12.30-14.10$ & & \\
\hline Sabtu & $08.50-10.30$ & Q5 & Pancasila \\
\hline
\end{tabular}




\begin{tabular}{|c|c|c|c|}
\hline Senin & $10.40-12.20$ & Q6 & Bahasa Indonesia \\
\hline Selasa & $16.10-17.50$ & Q6 & \\
\hline Rabu & $12.30-14.10$ & Q6 & Pancasila \\
\hline Kamis & $\begin{array}{l}14.20-16.00 \\
08.50-10.30 \\
14.20-16.00\end{array}$ & Q6 & ISBD \\
\hline Jumat & $\begin{array}{l}08.50-10.30 \\
12.30-14.10 \\
18.00-19.40\end{array}$ & Q6 & $\begin{array}{l}\text { Agama Kristen } \\
\text { Bahasa inggris II }\end{array}$ \\
\hline $\begin{array}{l}\text { Sabtu } \\
\text { Senin }\end{array}$ & $\begin{array}{l}18.00-19.40 \\
07.00-08.40\end{array}$ & $\begin{array}{l}\text { Q6 } \\
\text { Q7 }\end{array}$ & Bahasa inggris I \\
\hline Selasa & $\begin{array}{l}08.50-10.30 \\
10.40-12.20 \\
16.10-17.50\end{array}$ & Q7 & $\begin{array}{l}\text { Bahasa Indonesia } \\
\text { Pancasila }\end{array}$ \\
\hline Rabu & $14.20-14.10$ & Q7 & ISBD \\
\hline Kamis & $\begin{array}{l}08.50-10.30 \\
14.20-16.00\end{array}$ & Q7 & $\begin{array}{l}\text { Pancasila } \\
\text { Agama Kristen }\end{array}$ \\
\hline Jumat & $\begin{array}{l}08.50-10.30 \\
18.00-19.40\end{array}$ & Q7 & \\
\hline Sabtu & $07.00-08.40$ & Q7 & Agama Kristen \\
\hline \multirow[t]{2}{*}{ Selasa } & $\begin{array}{l}12.30-14.10 \\
14.20-16.00 \\
16.10-17.50\end{array}$ & Q8 & $\begin{array}{l}\text { Pancasila } \\
\text { Bahasa Indonesia }\end{array}$ \\
\hline & $18.00-19.40$ & & Agama Kristen \\
\hline \multirow[t]{2}{*}{ Rabu } & $\begin{array}{l}07.00-08.40 \\
08.50-10.30\end{array}$ & Q8 & \\
\hline & $\begin{array}{l}10.40-12.20 \\
16.10-17.50\end{array}$ & & $\begin{array}{l}\text { Agama Kristen } \\
\text { ISBD }\end{array}$ \\
\hline Jumat & $14.20-16.00$ & Q8 & \\
\hline Sabtu & 18.00-19.4- & Q8 & ISBD \\
\hline Selasa & $\begin{array}{l}12.30-14.10 \\
16.10-17.50\end{array}$ & Q9 & Bahasa Indonesia \\
\hline Rabu & $07.00-08.40$ & Q9 & Agama Kristen \\
\hline Kamis & $\begin{array}{l}16.10-17.50 \\
18.00-19.40\end{array}$ & Q9 & Bahasa inggris II \\
\hline Jumat & $10.40-12.20$ & Q9 & Agama Kristen \\
\hline \multirow[t]{2}{*}{ Sabtu } & $\begin{array}{l}07.00-08.40 \\
08.50-10.30\end{array}$ & Q9 & Pancasila \\
\hline & $\begin{array}{l}14.20-16.00 \\
18.00-19.40\end{array}$ & & Agama Kristen \\
\hline Senin & $\begin{array}{l}10.40-12.20 \\
12.30-14.10 \\
16.10-17.50\end{array}$ & Q10 & $\begin{array}{l}\text { Agama Kristen } \\
\text { Pancasila }\end{array}$ \\
\hline Senin & $18.00-19.40$ & Q10 & \\
\hline \multirow[t]{2}{*}{ Selasa } & $\begin{array}{l}07.00-08.40 \\
12.30-14.10\end{array}$ & Q10 & \\
\hline & $18.00-19.40$ & & Agama Kristen \\
\hline Rabu & $16.10-17,50$ & Q10 & \\
\hline Sabtu & $12.30-14.10$ & Q10 & \\
\hline Sabtu & $16.10-17.50$ & Q10 & Pancasila \\
\hline
\end{tabular}

b. Masalah penjadwalan dapat diselesaikan menggunakan software Lingo 11.0 mendapatkan solusi optimal yaitu19 ruangan perkuliahan yang di gunakan untuk proses perkuliahan menjadi 5 ruangan.

Pada tabel 5 dan tabel 6 merupakan hasil dari meminimumkan ruangan pada penjadwalan mata kuliah dasar umum (MKDU). Masalah tersebut dapat di selesaikan menggunakan metode Integer Linier Progamming dengan alat bantu software LINGO 11.0, solusi optimal yang diperoleh dari 19 ruangan yang tersedia atau yang digunakan untuk melakukan kegiatan perkuliahan menjadi 5 ruangan. Sehingga tidak terjadi penumpukan mata kuliah, bentroknya ruang kuliah yang dipakai. Hasil penjadwalan ini terdapat dua solusi penjadwalan yaitu solusi $P$ dan $Q$, solusi ini tidak termaksud $P$ untuk kelas pagi dan $Q$ untuk kelas sore namun dari dua solusi ini dapat di masukan program studi, mata kuliah yang sesuai dengan periode waktu yang ada. Hasil penjadwalan ini sudah optimal di isi dengan 10 program studi terlepas dari program studi Pendidikan guru sekolah dasar dan agribisnis kelas sore, ada kolom-kolom periode waktu yang belum di isi dengan mata kuliah dapat di isi dengan memenuhi kolom periode waktu yang tersedia.

\section{Simpulan}

Universitas Tribuana Kalabahi merupakan salah satu universitas yang ada di Nusa Tenggara Timur,kabupaten Alor. Di universitas Tribuana Kalabahi sudah di Bagi beberapa unit dalam membantu menjalankan tugas masingmasing. Salah satu unit yang ada di Universitas adalah Unit mata kuliah dasar umum (MKDU). Unit ini tugasnya adalah membuat penjadwalan mata kuliah dasar umum bagi seluruh dosen dan juga mahasiswa yang aktif kuliah di Universitas Tribuana Kalabahi.Setelah melakukan penelitian mengenai penjadwalan perkuliahan pada Unit MKDU dengan menggunakan integer linier programming dengan alat bantu software Lingo 11.0 di dapat kesimpulan sebagai berikut.

a. Fungsi tujuan dan fungsi kendala dalam penjadwalan dapat di rumuskan dalam model matematika dengan menggunakan Integer Linier Progamming.

\section{Pustaka}

Anderson, David R., Sweeney, Denis J., dan William, Thomas A. 1996. Manajemen sains Pendekatan kuantitatif untuk pengambilan keputusan manajemen, terjemahan Ancella Ancella A. Hermawan dari an introduction to management science Quantitative Approach to Decision Making. Jakarta: Penerbit Erlangga.

Blegur, F.M.A. dan Binsasi, E. 2020. Goal Programming untuk optimasi jadwal perkuliahan pada Fakultas Pertanian UNIMOR, 51-54.

Daskalaki, S., T. Birbas and E. Housos. 2004. An Integer Programming Formulation for A Case Study in University Timetabling. European Journal of Operational Research. 153 (1):117-135.

Daskalaki, S., T. Birbas and E. Housos. 2008. School Timetabling for Quality Student and Teacher Schedules. Journal of Scheduling. 12: 177-197.

Hikma, Nusyafitri Amin. 2015. Aplikasi Integer Linier Programming (ILP) Untuk meminimumkan biaya produksi pada Siaputo Aluminium, $128-135$.

Khairunnisa. 2015. Penjadwalan Perkuliahan Otomatis. Fibonacci Jurnal Pendidikan Matematika \& Matematika. 1(1): 1-14.

Huda, N.N., Dharma, I.G.B.B. \& Wasityastuti, W. 2016. Aplikasi Metode Sequential Three-Stage Integer Goal Programming untuk Penjadwalan Kuliah Pendidikan Dokter Sistem Blok: Studi Kasus. Jurnal Pendidikan Kedokteran Indonesia. 5(1): 29-44.

Maspaitella, B. J. dan Tupan, J. M. 2016. Model Integer Programming (studi kasus pada pada Jurusan Teknik Universitas Patimura Ambon).

Oktavia, M., A. Aman and T. Bakhtiar. 2017. Courses timetabling problem by minimizing the number of less preferable time slots," IOP Conference Series: Materials Science and Engineering, vol. 166, p. 012025.

Ruhiyati, F. H. 2015. Penjadwalan perkuliahan Menggunakan Goal Programming :Studi Kasus S1 Matematika FMIPA IPB. 46-56. 